
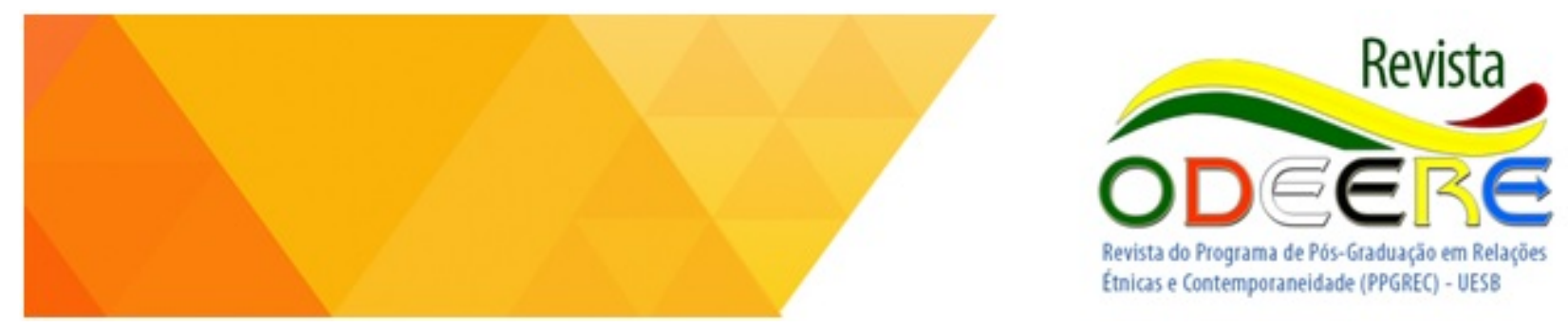

\section{A QUESTÃO DO}

\section{AUTOCONHECI-}

\author{
MENTO NA
}

FILOSOFIA DE

\author{
ORUNMILÁ
}

\section{THE QUESTION \\ OF SELF-}

KNOWLEDGE IN

THE

\section{PHILOSOPHY OF ORUNMILÁ}

\author{
Renato Noguera \\ Universidade Federal Rural do Rio de \\ Janeiro (UFRRJ) \\ renatonoguera@ymail.com
}

\section{Resumo:}

Partindo da ideia de Orunmilá que filosofia é autoconhecimento, este artigo pretende apresentar dois aspectos deste pensamento: ciência da cabeça e cartografia dos caminhos. Nós vamos fazer uma breve incursão em arranjos matemáticos sobre Odu Ifá, analisando os elementos que constituem a cabeça (ori) e as encruzilhadas dos caminhos. A base teórica está situada nos escritos de filósofas(os) nigerianas(os), principalmente Sophie Oluwole.

Palavras-chave: Orunmilá; filosofia; autoconhecimento; ori; caminhos.

\begin{abstract}
:
Starting from ideia's Orunmilá that philosophy is selfknowledge, this article aims to present two aspects of this thougt: head science and path mapping. Let's make a brief foray Mathematical Arregements about Odu Ifa, analyzing the elements that constitute the head (ori) and the crossroads of the paths. The theoretical basis is found in the writings of Nigerian philosophers, mainly Sophie Oluwole.
\end{abstract}

Key-words: Òrúnmilá; Philosophy; Selfknowledge; Ori; Paths. 


\section{Introdução}

A imagem clássica do surgimento da filosofia na Grécia antiga traz junto um enunciado que criticamos. A história da filosofia ocidental opera com a hipótese de que o pensamento filosófico se diferenciou do mito especificamente por volta do século VI antes da Era Comum (a. E.C.) nas colônias gregas insulares. Essa formulação está presente em escritos de consagrados historiadores da filosofia como Émile Bréhier ${ }^{1}$ (1997) e presente em diversos textos de introdução à filosofia ${ }^{2}$. Pois bem, o filósofo italiano Robert Bernasconi ajuda a objetar essa hipótese - sem dúvida transformada inadvertidamente numa tese praticamente dogmática. Para Bernasconi, a cisão entre mito e filosofia ocorre efetivamente durante o período do renascimento europeu, quando a emergência de um projeto de racionalidade parece impor um distanciamento radical dos elementos mítico-religiosos que sempre fizeram parte do pensamento filosófico ${ }^{3}$. Nós podemos dizer que os comentadores modernos procuraram "limpar" o discurso filosófico de "ruídos" míticos. Porque durante toda antiguidade, assim como no período medieval, esse divórcio não existia. O discípulo de Sócrates, o célebre filósofo grego Platão, afirma que Sócrates tinha formulações filosóficas sobre temas como a eternidade da alma e antes de ter sua condenação preocupou-se com um compromisso com os deuses. Na obra Fedro, Sócrates pediu que Critón pagasse um sacrifício ao deus Asclépio.

Sócrates já se tinha tornado rijo e frio em quase toda região inferior do ventre, quando (...) disse estas palavras, as derradeiras que pronunciou: Críton, devemos um galo a Asclépio; não te esqueças de pagar essa dívida. Assim farei, respondeu Críton. Mas vê se não tem mais alguma coisa para dizer-nos. A pergunta de Críton ficou sem resposta ${ }^{4}$.

Pois bem, esta formulação não deve ser vista como um aspecto menor da filosofia socrático-platônica. Além de Bernasconi, outros pensadores ajudam a desfazer essa oposição entre mito e filosofia.

(...) pode-se falar da existência, em certos filósofos da Antiguidade, de um sentimento do sagrado, que se relaciona tanto com o cosmos como com a própria vida interior e suas profundezas, sentimento cuja intensidade pode chegar até a experiência mística ${ }^{5}$.

\footnotetext{
${ }^{1}$ BRÉHIER, Émile. História da filosofia. Tradução Eduardo Sucupira Filho. São Paulo: Mestre Jou, 1977.

${ }^{2}$ CHAUÍ, Marilena. Iniciação à filosofia. São Paulo: Ática, 2011, e, COTRIM, Gilberto. Fundamentos da filosofia: ser, saber e fazer. São Paulo: Editora Saraiva, 2011.

3 BERNASCONI, Robert. Etnicidade, cultura e filosofia. In: BUNNIN, Nicholas e TSUI-JAMES, E. P. (org.) Compêndio de Filosofia. Trad. Luiz Paulo Rouanet. 2. ed. São Paulo: Edições Loyola, 2007. p.611- 625.

${ }^{4}$ PLATÃO. Fédon. Tradução de Jorge Paleikat e João Cruz Costa. São Paulo: Abril Cultural, 1972, 118b.

5 HADOT, Pierre. Exercícios espirituais e filosofia antiga. Tradução de F. Loque e L. Oliveira. São Paulo: É Realizações, 2014, p.288.
} 
Essa breve digressão situando os gregos na filosofia tem como objetivo apenas ressalvar que a cisão entre mito e filosofia é equívoca. Daí, na esteira das considerações da filósofa nigeriana Sophie Oluwole, mitos são fontes de pensamento filosófico e os textos de filosofia não estão em oposição, ou ainda, numa diferenciação radical e substancial em relação aos mitos. Dito isso, a partir de algumas narrativas da cosmologia iorubá, vamos analisar uma das questões-chave do pensamento de Orunmilá: a filosofia pode ser definida como arte de viver na produção de sentido. Ou ainda, modo de vida orientado pelo autoconhecimento. O que parece muito com a formulação hadotiana: "filosofia, na época helenística e romana, apresenta-se então como um modo de vida, como uma arte de viver" ${ }^{6}$. É interessante notar que os registros da filosofia de Orunmilá, como veremos a seguir, são anteriores aos textos greco-romanos do século IV a.E.C.

\section{As três caracterizações de Orunmilá}

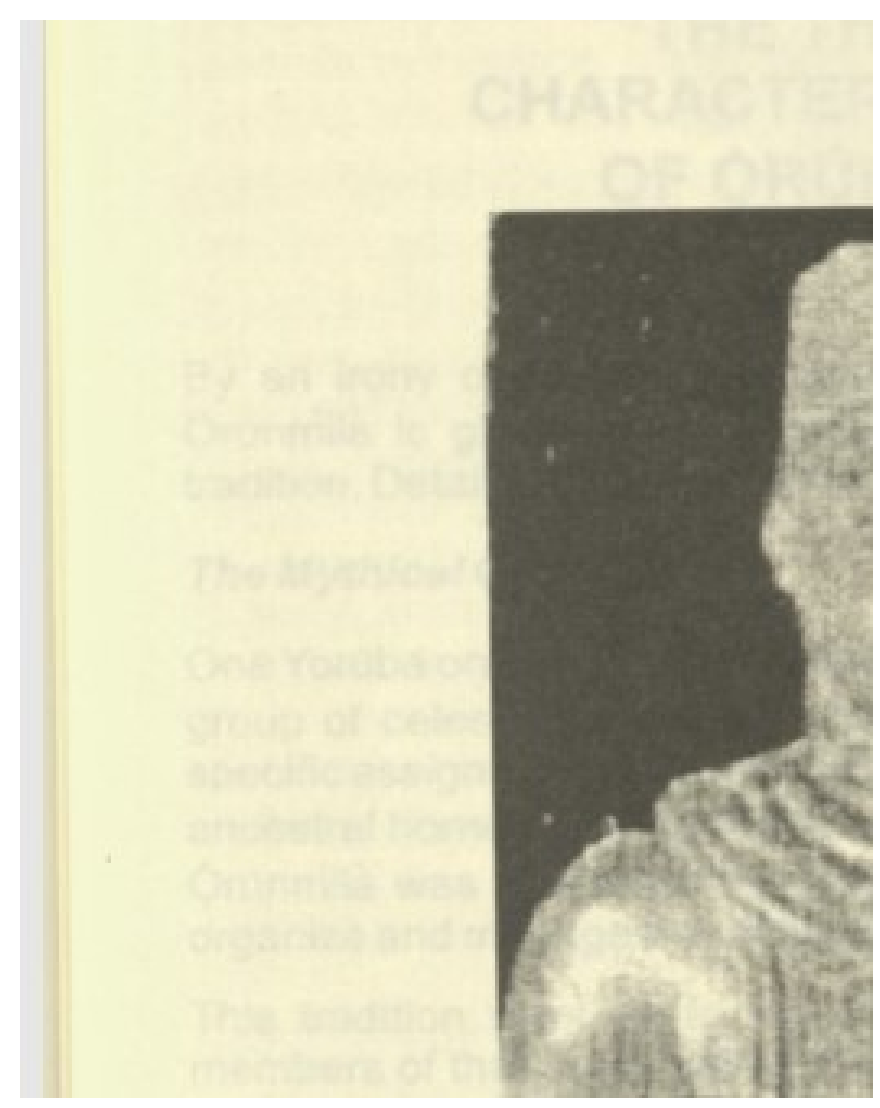

Figura $01^{7}$

A filósofa nigeriana Sophie Oluwole tem um trabalho pioneiro. Em Socrates and Orunmila: Two Patron Saint of classical Philosophy apresenta três caracterizações de Orunmilá ${ }^{8}$. Conforme

\footnotetext{
${ }^{6}$ Ibidem , p. 271.

${ }^{7}$ OLUWOLE, Sophie. Socrates and Orunmila: Two Patron Saint of classical Philosophy. $3^{\text {a }}$ ed. Lagos: Ark Publishers, 2017, p. 41.

${ }^{8}$ Ibidem, p. 43.
} 
Oluwole, o nome Orunmilá circunscreve três possibilidades que aqui descreveremos como: 1ํ) Orunmilá mítico; 2ํ) Orunmilá corporativo; 3ํ) Orunmilá histórico. No primeiro caso, trata-se de uma dimensão mítico-religiosa que no contexto iorubá remete ao orixá responsável pelos

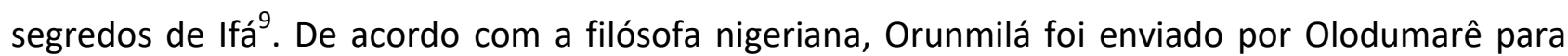
dar direção e sentido para os seres humanos em seus percursos. Olodumarê é o Deus todo poderoso, onipotente, senhor da realidade profunda, extensa e permanente. Orunmilá é um orixá, um ser celestial, uma divindade guardiã de Ifá. A partir de alguns trabalhos ${ }^{10}$, entendemos Ifá como um sistema divinatório estruturado de modo complexo a partir de arranjos que envolvem basicamente 16 odus (caminhos) resultando em 256 possibilidades para cada circunstância. Orunmilá é denominado de Olorun Ogbon, isto é, Deus da Sabedoria. A divindade que conhece o segredo dos caminhos e cabeça (ori) dos outros orixás e dos seres humanos. Em termos filosóficos, tomando por bases estudos de Maulana Karenga ${ }^{11}$, o conhecimento mais profundo, extenso e permanente está numa compreensão cartográfica dos caminhos que existem e da maneira como orixás e pessoas transitam por eles. Com base nas formulações de Karenga e Abimbola, Orunmilá é o orixá que testemunha a criação de todos os seres humanos, isto é, conhece as possibilidades do destino - aqui entendido como arranjos possíveis durante um percurso.

A segunda caracterização é de ordem corporativa e institucional, ou ainda: trata-se de uma função sociocultural que funciona como signo da preservação simbólica do patrimônio intelectual de um povo material Neste caso, o nome "Orunmilá" funciona como um título concedido às pessoas que reúnem uma série de conhecimentos acerca de Ifá. Nas palavras de Sophie Oluwole, Orunmilá pode ser lido como "uma expressão da natureza da realidade e os princípios de seu entendimento $^{\prime 12}$. O que remeteria ao caráter de buscar a sabedoria, investir no conhecimento profundo. Orunmilá é um vocativo, um conjunto de práticas que algumas pessoas colocam em exercício à medida que vivenciam o aprendizado reconhecendo que "nenhum ser humano possui conhecimento e sabedoria absolutas" ${ }^{13}$. Por fim, a terceira caracterização emerge de uma

\footnotetext{
${ }^{9}$ NOGUERA, Renato. Mulheres e deusas: como as divindades e os mitos femininos formaram a mulher atual. Rio de Janeiro: Harper Collins, 2017, p.68.

10 ABIMBOLA, Wande. An exposition of Ifá literacy corpus. Ibadan e Londres, Oxford University Press. 1981. ADEGBINDIN, Omotade. Ifá in Yorùbá thought system. Durham, North Carolina. Carolina Academic Press. Library of Congress Cataloging-in-publication data, 2014. ADEGBOYEGA Oyekunle Oluwayemisi. The metaphysical and epistemological relevance of ifa corpus. In: International Journal of History and Philosophical Research. Vol.5, No.1, pp.28-40, February 2017.

${ }^{11}$ KARENGA, Maulana. Odu Ifa: the etical teachings. Los Angeles: University Sankore Press, 1999.

${ }^{12}$ OLUWOLE, Sophie. Socrates and Orunmila: Two Patron Saint of classical Philosophy. $3^{\mathrm{a}}$ ed. Lagos: Ark Publishers, 2017, p. 44.

${ }^{13}$ Ibidem, p. 52.
} 
narrativa antiga ${ }^{14}$. De acordo com Abosede Emanuel, Orunmilá foi um próspero filósofo, casado com Iwa descrito como um grande pai. Ele teve muitos seguidores; mas, 16 foram mais próximos receberam os ensinamentos de um sistema que passou a ser designado como Odu Ifá.

\section{A linguagem em questão}

Uma maneira de trazer à luz as reflexões filosóficas de Orunmilá está na leitura dos filósofos nigerianos Wande Abimbola ${ }^{15}$ e Omotade Adegbindin ${ }^{16}$. A partir dessas leituras, vamos lançar mão de uma versão da consagração do orixá Orunmilá como guardião de Ifá.

Nos tempos imemoriais, Olodumarê encarregou seu filho Obatalá, o senhor do pano branco, de definir dentre orixás, qual mais sabedoria teria. O motivo: definir quem Ifá guardaria. Obatalá precisou definir quem seria guardião de Ifá. Ele convidou Orunmilá para provar sua sabedoria, pediu-lhe que preparasse uma iguaria. Obatalá ordenou: "traga a melhor comida do mundo!". Orunmilá aceitou o desafio e não demorou muito. Ele seguiu para a cozinha colocou fogo na madeira, água na panela; do touro trouxe a língua e da plantação, inhame. Na água quente em panelas diferentes, língua e inhame. Um tempero com raízes e flores. Orunmilá levou o prato até Obatalá, este depois de comer comemorou alegremente a melhor comida do mundo. Orunmilá estava sorridente; mas, quando pensava em agradecer ficou mudo. Obatalá pediu que ele fizesse a pior comida do mundo e sem demorar muito voltou com um prato de língua de touro com inhame. O senhor do pano branco observou a iguaria espantado, olhos esbugalhados, pensando: "como pode o mesmo prato ser o melhor e o pior?". Mas, depois de comer confirmou que Orunmilá tinha acertado e, com a graça de Olodumarê, o consagrou senhor dos segredos de Ifá.

Uma incursão "exegética" sobre a narrativa pode lançar algumas luzes sob aspectos que podem parecer herméticos à primeira vista. Por que Orunmilá usa língua de touro? Por que o inhame? No contexto iorubá e de muitos povos tradicionais africanos, o touro é um animal que quando abatido é completamente usado. O chifre e ossos para confeccionar instrumentos, todas as partes do corpo para alimentação, o couro para produção de roupas e calçados, o sangue para rituais e usos de adubo. Em outras palavras, o touro pode ser considerado o que garante a vida, ou ainda, toda a realidade. O inhame é um resultado da plantação, de trabalho de arar e semear a terra. A agricultura é uma dimensão fundamental da vida humana, sem plantar e colher as

\footnotetext{
${ }^{14}$ EMANUEL, Abosede. Ifa festival, Odun lie. Lagos: West African Book Publishers Limited, 2000, p. 233.

${ }^{15}$ Op.cit.

${ }^{16}$ Op.cit.
}

Odeere: Revista do Programa de Pós-Graduação em Relações Étnicas e Contemporaneidade - UESB. ISSN: 2525-4715 - Ano 2018, Volume 3, número 6, Julho - Dezembro de 2018. 
condições de existir seriam mais facilmente suprimidas. O que remete à ideia de cultivo, cuidado para fazer surgir, em certa medida, cultura (do inhame). Por outro lado, a língua do touro aponta nitidamente para ideia de linguagem. A interpretação que defendemos nesse artigo ensaístico é bem simples. A língua de touro é signo da linguagem, esta entendida como maneira fundamental de relação com a realidade e cultivo das condições de manutenção da vida. O touro é signo da totalidade da realidade, o inhame funciona como signo do cultivo. $\mathrm{O}$ ato de comer de Obatalá e as opiniões diversas sobre o mesmo prato indicam que a vida é uma experiência complexa em que os acontecimentos não possuem um valor absoluto. Os valores estão localizados nas maneiras de relacionamento com os acontecimentos.

A linguagem é um modo de instalar realidade e cultivar modos de vida. Em outros termos, ela é um modo de relação com o mundo e a partir do qual cultivamos maneiras de ser e experimentar a vida. A linguagem que permite estabelecer tanto modos singulares quanto maneiras gerais e impessoais com o mundo. A linguagem aqui não está restrita aos modos verbais e não-verbais de conversação. Mas, além dos gestos e palavras, os modos de vestir sejam os uniformes ou os cortes de cabelo e as maneiras de fazer as coisas. Por exemplo, uma pessoa recém-iniciada no candomblé usa branco e outros aparatos específicos. Uma pessoa em serviço militar veste um uniforme.

Dentre as maneiras de interpretar a história, a língua de touro significa palavra. A palavra tem um poder incrível. Conforme Hampaté Bâ, ela "pode criar paz, assim como destruí-la”"17. Ou seja, através da linguagem que incitamos a paz ou a guerra. A linguagem consagra, agradece e reclama suavemente propondo um caminho; mas, também amaldiçoa e reclama sem dar solução. A linguagem é um modo de imprimir realidades. Por essa razão, "a língua de touro com inhame" pode ser um ótimo prato ou uma péssima comida. O que está em jogo é o preparo da linguagem, o uso das palavras. A maneira como interpretamos a realidade e a fazemos circular pelos modos de dizer.

\section{O autoconhecimento em questão}

Uma das caracterizações mais adequadas para definir a filosofia de Orunmilá é como um modo de vida que se ocupa de duas atividades: conhecer a própria cabeça (ciência da cabeça) e mapear antecipadamente os caminhos a serem percorridos (cartografia dos caminhos). 0

\footnotetext{
${ }^{17} \mathrm{BÂ}$, Amadou Hampaté. A Tradição Viva. In: KI-ZERBO, Joseph (ed.). História geral da África I: Metodologia e préhistória da África. - 2.ed. rev. - Brasília: UNESCO, 2010, p. 173. 
exercício filosófico consiste basicamente em dar conta dessas duas atividades. A partir de uma caracterização de que a realidade é composta por quatro elementos: ar, terra, água e fogo. Ou seja, tanto as cabeças humanas como os caminhos são feitos dos quatro elementos em arranjos específicos que vão definir os modos de ser do sujeito. O mesmo se dá com os caminhos. O que leva-nos a um conjunto de procedimentos matemáticos denominado de análise combinatória que compreende operações específicas como permutação, combinação e arranjo ${ }^{18}$. Para entendermos a filosofia de Orunmilá, seja na "ciência da cabeça" e na "cartografia dos caminhos" precisamos compreender a natureza de arranjos simples matemáticos. De modo geral, a análise combinatória retrata um conjunto de possibilidade constituído por elementos finitos, a mesma baseia-se em critérios que possibilitam a contagem e compreende três "operações" permutação, arranjo e combinação. Aqui nos interessa o arranjo que remete justamente a levar em consideração a ordem dos elementos. De acordo com o matemático especialista em educação matemática Ricardo $\mathrm{Sabo}^{19}$, arranjo simples de $n$ elementos tomados $p$ a $p$, onde $n>=1$ e $p$ é um número natural, é qualquer ordenação de $p$ elementos dentre os $n$ elementos, em que cada maneira de tomar os elementos se diferenciam pela ordem e natureza dos elementos. A fórmula para cálculo de arranjo simples é dada por:

$$
A_{n, p}=\frac{n !}{(n-p) !}
$$

Essa fórmula serve para calcularmos e entendermos tanto a cabeça quanto os caminhos. Por cabeça, ori em iorubá, devemos entender o que constitui e caracteriza cada pessoa. Em termos filosóficos, ori é o que constitui o sujeito em todos os seus aspectos. Um ori tem sempre quatro lados. Nós vamos usar uma metáfora simples para argumentar melhor a respeito da natureza do sujeito. Como já foi dito, Orunmilá testemunha a criação das cabeças. O responsável pela produção é um fiel encarregado de Obatalá, o orixá Ajalá.

Cada ser humano deverá ser modelado no Orum, por Ajalá, o oleiro, com matéria sutil e imperceptível ao mundo que irá habitar. Depois, eles receberão corpos de carne, que serão exatamente iguais aos protótipos aqui modelados. Esses corpos deverão, por sua vez, ser moldados com a matéria grosseira do novo mundo, a lama, de onde tudo provém. Após

\footnotetext{
${ }^{18}$ ALVES, Renato; SEGADAS, Claudia. Sobre o ensino da análise combinatória: fatores a serem considerados, lacunas a serem evitadas. Acta Scientiae, Canoas, v. 14, n. 3, p. 405- 420, 2012.

${ }^{19}$ SABO, Ricardo Dezso. Saberes docentes: análise combinatória no ensino médio. Dissertação (Mestrado em Educação Matemática). São Paulo: Pontifícia Universidade Católica de São Paulo, 2010, p. 86-87.
} 
haverem cumprido sobre a Terra a missão a que foram destinados, serão tocados por Iku e, separados de meu Espírito, devolvidos à Terra, para que voltem a ser apenas lama. ${ }^{20}$

Para fins de compreensão filosófica, vamos usar a seguinte metáfora, o ori tem "quatro cantos" do ori precisam ser preenchidos por 100 búzios. Estes, por sua vez, sendo formados pelos quatro elementos. O arranjo e disposição modificará o modo de ser de cada sujeito. Os quatro cantos de ori são: ojuori (a testa), icoco ori (a nuca), otum (o lado direito), ossi (o lado esquerdo). Cada canto de ori, ou ainda, direção tem uma função específica no funcionamento, disposições e maneiras de pensar, sentir e agir de um sujeito. Nós podemos ter arranjos variados. Um ori composto pelo seguinte arranjo: ar(testa), fogo(nuca), terra (direita), água (esquerda). Outros podem combinação semelhante. Mas, uma alteração de orem modifica bastante. Por exemplo, ar (testa), terra(nuca), fogo (direita), água (esquerda). Mas, ainda que dois oris sejam aparentemente idênticos, isso não é totalmente verdadeiro. Vejamos a seguinte situação: Ori de sujeito A apresenta o seguinte arranjo: água (testa), água (nuca), água (direita), água (esquerda). Ori de sujeito B, água (testa), água (nuca), água (direita), água (esquerda). Porém, o elemento água, assim como todos os outros, possui maneiras diversas de manifestação. O elemento água pode ser regido por orixás, tais como: lemanjá e Oxum. Em linhas gerais, lemanjá remete às águas do mar, enquanto Oxum às águas doces. Porém, as águas do mar podem mansas e cristalinas, mas, também, podem ser revoltas devido água de chuva com vento ou verdadeiros maremotos causados somente por ventanias secas e frias; assim como águas doces são diversas e podem ser de cachoeira, de lagoas ou rios, por exemplo. Sem contar combinações complexas em que dois elementos ocupam em possibilidades variadas um mesmo canto. Nós podemos apresentar um ori com arranjo mais detalhado: terra com ar em movimento [ventania] (testa), fogo com ar brando [brisa] (nuca), água doce (direita), água de mar revolto (esquerda). Esses elementos assumem formas que por serem variáveis emprestam o tom de complexidade no processo de autoconhecimento. Um aspecto-chave da filosofia de Orunmilá está na ciência da cabeça, isto é, determinar a constituição interna de um sujeito, como os quatro elementos estão dispostos nos cantos do ori e qual tipologia de cada elemento. Uma incursão mais demorada sobre a ciência da cabeça traz à luz que precisamos pensar os elementos em duplas dentro dos quatro cantos da cabeça. O que fica exposto na fórmula abaixo:

$$
A_{8,4}=\frac{8 !}{(8-4) !}=1680
$$

\footnotetext{
${ }^{20}$ ADILSON DE OXALÁ. Igbadu, a cabaça da existência: mitos nagôs revelados. Rio de Janeiro: Pallas, 2001, p.55 
Com o resultado de 1680 tipos básicos de sujeitos. Nós temos uma base estrutural da consistência do sujeito e, a partir desse elemento, articulamos com a cartografia dos caminhos que possuem 256 possibilidades. De onde concluímos que parcialmente existem milhares de maneiras básicas de transitar $(1680 \times 256=430.080)$, isto é, de viver. Pois bem, levando essa complexidade em conta. A primeira recomendação filosófica de Orunmilá é a leitura de si. Todo sujeito deve se ocupar de si. Não num sentido narcísico em que o espelho mostra apenas a própria imagem; mas, na perspectiva do espelho de Oxum. Em diversas narrativas mítico-religiosas, Orunmilá aparece como esposo de Oxum. Não é raro encontrarmos interpretações da narrativa do casamento de Orunmilá com Oxum nas quais, a orixá aprende com o orixá. Aqui é importante destacar o inverso, o que ele aprende com ela? É importante dizer que o casal celebrou um acordo no qual ensinariam tudo que sabiam para a "pessoa" amada. Uma das coisas que Orunmilá aprendeu foi a usar o espelho de Oxum, um espelho que não tem como função principal apresentar o reflexo de quem o encara; mas, mostrar o passado. Em outros termos, demonstrar o percurso que tornou possível que o sujeito esteja onde está.

Com efeito, antes de fazer qualquer coisa: "é preciso saber quem você". Ora, isso inclui reconhecer a própria história familiar, ancestral, o seu solo cultural, as relações sociais, em outros termos, os caminhos que conduzem um sujeito ao ponto no qual se encontra no presente. Porém, saber sobre si não é suficiente. $\mathrm{O}$ autoconhecimento tem como quesito necessário a ciência da cabeça; mas, somente estará pleno acrescido de uma cartografia dos caminhos. Porque o ori sempre percorre caminhos, atravessa por encruzilhadas. De onde é indispensável compreender os caminhos possíveis e entender previamente, considerando a natureza do ori, como ele se movimentará. É a partir dos arranjos entre ori e caminhos que algumas pessoas podem estar de bem ou de mal com suas existências. O papel do autoconhecimento está em viver de bem consigo. Num quadro de arranjo simples temos os 16 caminhos.

\begin{tabular}{|l|l|l|l|}
\hline Caminhos do Ar & Caminhos da Água & Caminhos da Terra & Caminhos do Fogo \\
\hline Ar com Ar & Água com Ar & Terra com Ar & Fogo com Ar \\
\hline Ar com Água & Água com Água & Terra com Água & Fogo com Água \\
\hline Ar com Terra & Água com Terra & Terra com Terra & Fogo com Terra \\
\hline Ar com Fogo & Água com Fogo & Terra com Fogo & Fogo com Fogo \\
\hline
\end{tabular}

Esses caminhos são multiplicados, combinados com mais 16 possibilidades de desdobramentos (16 x 16), totalizando 256 caminhos possíveis. É importante registrar que os 
caminhos são sempre encruzilhadas formadas por quatro ruas diferentes: Rua de Ar; Rua de Água, Rua de Terra; Rua de Fogo. Abaixo uma ilustração necessária para intensificar a compreensão acerca do que estamos dizendo.

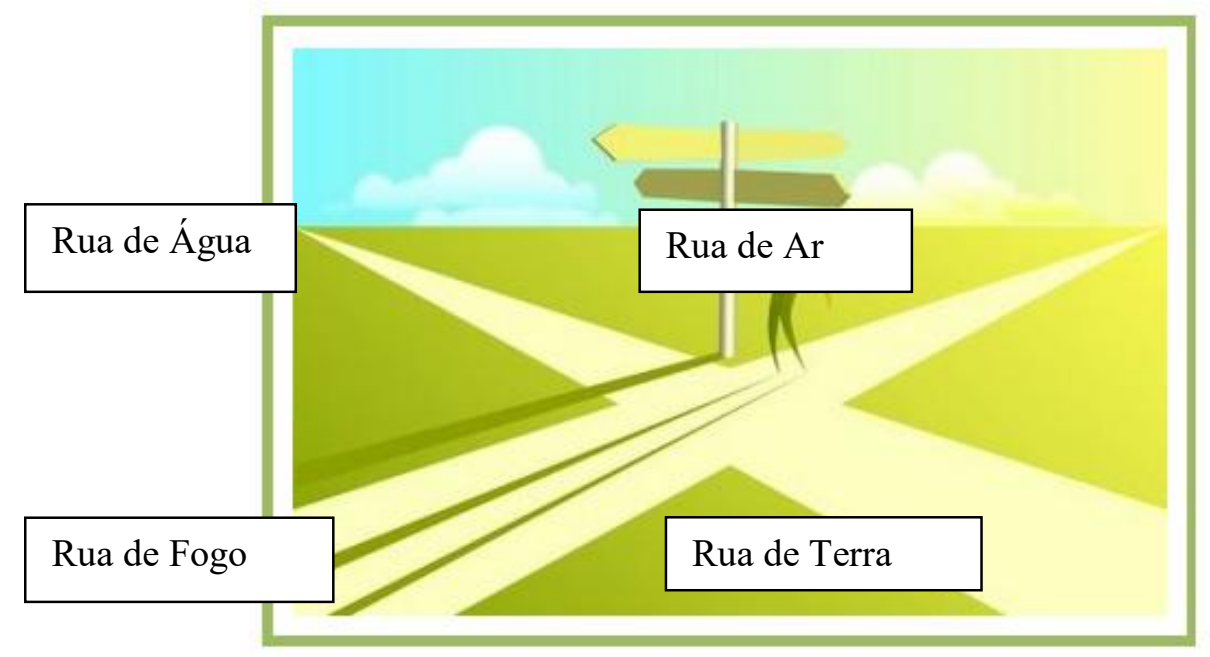

Figura $02^{21}$

O desenho acima dá uma dimensão do que estamos dizendo, um sujeito no meio de uma encruzilhada segue para Rua de Fogo. O que significa pensar as vidas como caminhos, encruzilhadas que começam com uma combinação entre quatro ruas, Rua do Ar, Rua da Água, Rua da Terra e Rua do Fogo. Essas ruas que se cortam como uma encruzilhada são os pontos de partida de todo ser humano. Pois bem todas as ruas desembocam em novas encruzilhadas que se bifurcam incessantemente. Cada ori se comportará de uma maneira durante o trajeto. Conforme essa perspectiva, em cada situação de escolha ou decisão uma pessoa tem 256 caminhos (alternativas). Como já dissemos anteriormente, todas as pessoas tem um ori. Importante frisar que as pessoas podem ser descritas como pessoas com base de ar, de água, de terra ou de fogo considerando a testa (o primeiro canto da cabeça). Mas, como sabemos esses elementos não caracterizam as pessoas isoladamente. As pessoas de ar podem ser de muitos tipos diferentes. Conforme o tipo de pessoa, o modo de andar pela Rua de Água será mais difícil ou mais simples, o que também se modifica dependendo do momento. Duas pessoas de base ar (testa) podem diferir muito. Por isso, as generalizações não ajudam muito. Portanto, dizer que uma pessoa de base ar é criativa não diz muita coisa sobre alguém. Porque de modo geral, pessoas de base ar são criativas, visionárias e sonhadoras; pessoas de base água são sensíveis, emotivas e cuidadoras; pessoas de base terra são práticas, organizadas e racionais; pessoas de base fogo são determinadas, desbravadoras e realizadoras. O que é relevante; mas, insuficiente. É preciso um detalhamento do

\footnotetext{
${ }^{21}$ Figura "escolha" disponível para uso retirada do Clip Art do Word Office.
} 
ori e um mapa bem definido das encruzilhadas, porque apenas, as interações entre o ori de alguém num determinado caminho podem dizer algo mais efetivo sobre um sujeito. Um desafio para compreensão do percurso a ser feito está no uso do tempo.

\section{Metodologia filosófica}

Paciência pode fazer o quente ficar frio e o frio se transformar em quente; ela também é capaz de deixar o amargo ficar doce porque sabe agradar seu pai, o Tempo, como ninguém. Por isso, ela não se queima e nem passa frio para sempre ${ }^{22}$.

O verso dá uma bela dimensão do orixá Paciência. Um dos mitos sobre Orunmilá explica que a divindade da sabedoria teve três opções para casar. Três belas deusas se apaixonaram por ele e queriam desposá-lo. As deusas eram a Discórdia, a Riqueza e a Paciência. Orunmilá escolheu a Paciência, a filha mais querida do Tempo. Então, Discórdia e Riqueza passaram a brigar. Outro verso das narrativas orais iorubás a respeito de Orunmilá diz: “Onde paciência existe, tudo se tem. Não se vive de bem sem paciência. Mas, não confunda paciência com esperar sem nada fazer, porque são coisas muito diferentes". Ora, depois de desposar a Paciência, a Discórdia e Riqueza resolveram viver com Orunmilá. O senhor dos segredos ficou com as três esposas e aprendeu com a Discórdia, a capacidade de duvidar, questionar e debater diante do óbvio e fácil. A Riqueza o presenteou com recursos e fartura.

Em especial, a Paciência é a deusa que permite Orunmilá realizar o que tem de mais decisivo na compreensão de si: a capacidade de observar. Paciência torna possível aprender consigo. Através da paciência uma pessoa pode conseguir observar a si mesma, suas reações diante dos acontecimentos sem ânsia de antecipar uma opinião sobre suas reações.

A Paciência entendida como jornada filosófica torna viável tanto o conhecimento do ori é sempre quádruplo, uma encruzilhada de um ou mais elementos. Como já foi visto o ori pode ser simbolizado como uma cruz, um " $x$ ", ou ainda, um sinal de "+". Os três símbolos significam que cada ser humano é basicamente a interseção dos quatro cantos. Pois bem, conhecer os elementos que ocupam esses cantos requer que o sujeito faça um caminhar que não se perca caminhando. $A$ descoberta de si surge durante a caminhada. Estar em acordo consigo ajuda a passar pelos caminhos que combinam com o seu ori. Em paralelo, somente conhecemos nosso ori caminhando. A paciência é a condição de possibilidade de aprender a estar em acordo consigo, ela que torna

\footnotetext{
${ }^{22}$ Verso que aprendi ainda na infância sobre a deusa Paciência.
} 
possível traçar um mapa. Uma pessoa impaciente tem mais chances de trilhar caminhos que a deixem em desacordo consigo. Esse estado de vida impede o autoconhecimento. Porque quando uma pessoa anda por caminhos que não permitem conhecer a si mesma, a ignorância aumenta. Conforme Orunmilá existem quatro tipos de relações com o conhecimento e a ignorância: 19) Uma pessoa que sabe e sabe que sabe; 2ㅇ) Uma pessoa que sabe; mas, não sabe que sabe; 3ํ) Uma pessoa que não sabe e sabe que não sabe; 4 ㅇ) Uma pessoa que não sabe; mas, acha que sabe. $A$ filosofia estaria na terceira maneira de relacionamento. Por isso, o seu papel é é dissipar, o máximo possível, a ignorância, mesmo que a recomendação de Orunmilá seja por reconhecer os limites do conhecimento e afirmar que entre as três formas de relação entre conhecimento e ignorância, apenas a terceira maneira é realmente filosófica. A paciência é a capacidade de investir no exercício de buscar conhecimento. Não se trata de esperar; mas, reconhecer que se as circunstâncias podem escapar ao controle e planejamento não pode resolver tudo, resta uma insistência resistente que modifique as estratégias para caminhar.

\section{Brevíssimas considerações finais}

"Para que serve a filosofia?", permanece uma indagação que ocupa tanto gente neófita quanto aquelas que já dedicaram décadas aos estudos filosóficos. Este artigo procurou contribuir com esse debate. A filosofia de Orunmilá tem um tema central e mais decisivo, o autoconhecimento. O fazer filosófico passa fundamentalmente por assumir a necessidade de sabermos quem somos. Para enfrentar essa demanda: nós convocamos um filósofo iorubá que viveu na região da atual Nigéria. Uma revisão bibliográfica panorâmica em bases de dados nacionais e até mesmo internacionais confirmou nossa hipótese, a saber, o nome de Orunmilá não aparece frequentemente vinculado à filosofia. Por isso, aqui demos algum destaque ao trabalho pioneiro de Sophie Oluwole, uma filósofa decisiva para difusão dos estudos do pensamento filosófico de Orunmilá. De qualquer maneira, este artigo procurou tratar de algum modo de um tema caríssimo à filosofia, o autoconhecimento, desvendando na medida do possível dois aspectos da filosofia de Orunmilá: uma ciência da cabeça ou do ori e uma cartografia dos caminhos.

O que a filosofia de Orunmilá ajuda a compreender é que na jornada existencial, o mais importante é conhecer a estrada e quem transita. Se recorrermos a uma comparação automobilística, para chegarmos num destino é preciso ter um mapa ou reconhecer indicações das placas no caminho e, antes disso, precisamos saber se o carro está com a revisão em dia (coisas do tipo: freio de disco do freio, óleo do motor), se o tanque de combustível está cheio e se 
é suficiente para o percurso pretendido, caso não seja: o abastecimento será obrigatório. Outros elementos como também precisam ser definidos antes, a estrada está em boas condições? A rodovia é privada e conta com cobrança para uso? Logo, é preciso confirmar os recursos disponíveis para completar o tanque de combustível e pagamento de pedágios. A filosofia de Orunmilá nos ajuda a fazer um percurso interessante a respeito do sistema de Odu Ifá. E, ao mesmo tempo, sobre a nossa natureza pessoal.

O estudo da filosofia de Orunmilá retoma algo fundamental na tarefa de pensar cuidadosamente, criticamente e criativamente (formas de filosofar): fazer um encontro sem fraudes consigo para uma escuta ativa e não fatalista da nossa condição e do que podemos fazer diante da instabilidade inerente à vida. O primeiro passo é paciência para a si mesmo e observar cuidadosamente os caminhos, avaliando as interações entre quem caminha e os caminhos.

\section{REFERÊNCIAS}

ABIMBOLA, Wande. An exposition of Ifá literacy corpus. Ibadan e Londres, Oxford University Press. 1981.

Sixteen Great Poems of Ifa. UNESCO, 1973.

. Ifá will mend our broken world: thoughts on Yoruba religion and culture in Africa and the diaspora. Roxbury, Massachusetts, Aim Books: 1997.

ADEGBINDIN, Omotade. Ifá in Yorùbá thought system. Durham, North Carolina. Carolina Academic Press. Library of Congress Cataloging-in-publication data. 2014.

ADEGBOYEGA Oyekunle Oluwayemisi. The metaphysical and epistemological relevance of ifa corpus. In: International Journal of History and Philosophical Research Vol.5, No.1, pp.28-40, February 2017.

ADILSON DE OXALÁ. Igbadu, a cabaça da existência: mitos nagôs revelados. Rio de Janeiro: Pallas, 2001.

ALVES, Renato; SEGADAS, Claudia. Sobre o ensino da análise combinatória: fatores a serem considerados, lacunas a serem evitadas. Acta Scientiae, Canoas, v. 14, n. 3, p. 405- 420, 2012.

BÂ, Amadou Hampaté. "A Tradição Viva” In KI-ZERBO, Joseph. História geral da África, I: Metodologia e pré-história da África. - 2.ed. rev. - Brasília : UNESCO, 2010.

BERNASCONI, Robert. "Etnicidade, cultura e filosofia”. In: BUNNIN, Nicholas e TSUI-JAMES, E. P. (org.) Compendio de Filosofia. Trad. Luiz Paulo Rouanet. 2. ed. São Paulo: Edições Loyola, 2007. p.611- 625

BRÉHIER, Émile. História da filosofia. Tradução Eduardo Sucupira Filho. São Paulo: Mestre Jou, 1977.

CHAUÍ, Marilena. Iniciação à filosofia. São Paulo: Ática, 2011.

COTRIM, Gilberto. Fundamentos da filosofia: ser, saber e fazer. São Paulo: Editora Sairava, 2011. 
DOORTMUNT, Michel R., The Roots of Yoruba Historiography: Classicism, Traditionalism and Pragmatism. In: FALOLA, Toyin (ed.). African Historiography. Burnt Mill: Longman, 1993.

EMANUEL, Abosede. Ifa festival, Odun lie. Lagos: West African Book Publishers Limited, 2000.

HADOT, Pierre. Exercícios espirituais e filosofia antiga. Tradução de F. Loque e L. Oliveira. São Paulo: É Realizações, 2014.

KARENGA, Maulana. Odu Ifa: the etical teachings. Los Angeles: University Sankore Press, 1999.

NOGUERA, Renato. Mulheres e deusas: como as divindades e os mitos femininos formaram a mulher atual. Rio de Janeiro: Harper Collins, 2017.

OLUWOLE, Sophie. Socrates and Orunmila: Two Patron Saint of classical Philosophy. 3a ed. Lagos: Ark Publishers, 2017.

PLATÃO. Fédon. Tradução de Jorge Paleikat e João Cruz Costa. São Paulo: Abril Cultural, 1972.

SABO, Ricardo Dezso. Saberes docentes: análise combinatória no ensino médio. Dissertação (Mestrado em Educação Matemática). São Paulo: Pontifícia Universidade Católica de São Paulo, 2010.

Renato Noguera: Renato Noguera é Professor do Departamento de Educação e Sociedade (DES), do Programa de Pós-Graduação em Filosofia, do Programa de Pós-Graduação em Educação, Contextos Contemporâneos e Demandas Populares (PPGEduc) da Universidade Federal Rural do Rio de Janeiro (UFRRJ), Pesquisador do Laboratório de Estudos Afro-Brasileiros e Indígenas (Leafro), e, do Laboratório Práxis Filosófica de Análise e Produção de Recursos Didáticos e Paradidáticos para o Ensino de Filosofia (Práxis Filosófica) da UFRRJ, Noguera coordena o Grupo de Pesquisa Afroperspectivas, Saberes e Infâncias (Afrosin), doutor em Filosofia pela Universidade Federal do Rio de Janeiro (UFRJ), Noguera está envolvido com três projetos de pesquisa: 1á) Filosofando com sotaques africanos e indígenas; 2a) Educação, Arte, Infância e Relações ÉtnicoRaciais: a literatura infantil a partir dos afro-rizomas e do perspectivismo ameríndio; 3a) "Modernidade" na perspectiva da Crítica da Razão Negra.

Artigo recebido para publicação em: Outubro de 2018.

Artigo aprovado para publicação em: Novembro de 2018. 